Journal of Advanced Research in Fluid Mechanics and Thermal Sciences

\title{
Analysis of MHD Flow and Heat Transfer of Casson fluid Flow Between Porous Disks
}

\author{
Devaki $\mathrm{B}^{1}$, Nityanand $\mathrm{P} \mathrm{Pai}^{1}$, Sampath Kumar $\vee \mathrm{S}^{1,{ }^{*}}$ \\ 1 Manipal Institute of Technology, Manipal Academy of Higher Education, Manipal, Karnataka, 576104, India
}

\begin{tabular}{|c|c|}
\hline ARTICLE INFO & ABSTRACT \\
\hline $\begin{array}{l}\text { Keywords: } \\
\text { Navier-stokes equations; laminar flow; } \\
\text { Casson fluid; non-linear differential } \\
\text { equations; homotopy perturbation } \\
\text { method; finite difference method }\end{array}$ & $\begin{array}{l}\text { A study is carried out for the two-dimensional Casson flow of conducting fluid in the } \\
\text { presence of a magnetic field. The governing non-linear equations of motion are } \\
\text { transformed in two dimensional form. A solution is obtained by the homotopy } \\
\text { perturbation method and it is valid for moderately large Reynolds numbers for } \\
\text { injection at the wall. Also, an efficient algorithm based finite difference scheme is } \\
\text { developed to solve the reduced coupled ordinary differential equations with necessary } \\
\text { boundary conditions. The effects of Reynolds number, the magnetic parameter, } \\
\text { pradantl number Casson parameter on flow velocity and temperature distribution is } \\
\text { analysed for increasing the non-Newtonian characteristics of the fluid by both the } \\
\text { methods and results agree well with previous work for special cases. It is observed that } \\
\text { the overall effect of magnetic field is same as Hartmann flow. Further the analysis } \\
\text { predicts that the heat transfer at the surface of the disks increases with increase in } \\
\text { Reynolds number, magnetic parameter and Prandtl number, shear stress at lower disk } \\
\text { also calculated. The study of such phenomenon is beneficial in the industry for thermal } \\
\text { control in polymeric processing. }\end{array}$ \\
\hline
\end{tabular}

\section{Introduction}

The flow of non-Newtonian conducting fluid between two porous disks is of practical importance in lubrication theory, such type of flow has lot of importance and applications in mechanical and manufacturing process, magnetic and storage devices (disk drives), gas engines, crystal growth process and bio-mechanics. MHD effects are used for power generators, light-ion-beam confinements, and spacecraft. Study about non-Newtonian fluids attracts many researchers because of its practical applications in various fields as mentioned above. Basic study about these types of fluid models done by Karman in 1921 [1], Batchelor [2] extended Karman work in 1967 for a flow over single disk. In 1960 many authors [3-5] done research about the fluid flow between rotating disks. In 1970 the Wang and his associates [6-8] analysed these type of models with different ideas like suction, injection and rotation of disks, this study makes very important and attracts many researchers in understanding of many practical and industrial applications. The first MHD analysis

\footnotetext{
* Corresponding author.

E-mail address: sampathkmr322@gmail.com
}

https://doi.org/10.37934/arfmts.83.1.4660 
about these types of models done by Srivastava and his associates in 1961 [9]. Later, many authors contributed the better analysis in MHD in this type models [10-12]. Further the problem was analysed by Stewartson [13] who found perturbation solution.

In reality fluid models involved are non-Newtonian. The complicated rheological properties better explained by non-Newtonian fluids. One such model is known to be Casson fluid model [14]. McDonald and Mrill $[15,16]$ showed that the blood type of flow can be analysed through Casson model. U. Khan and his associates present the unsteady squeezing flow of Casson fluid between parallel plates. Recently authors taken Casson model in their study and analysed under different conditions using various techniques.

Most of the problems discussed in the above literature are highly non-linear and associated with boundary conditions, many authors used numerical and semi-numerical methods to solve these types of models. One of the more efficient technique to solve such problems is the homotopy perturbation method (HPM). HPM first proposed by Ji-Huan He in 1998 [17]. HPM is the combination of traditional perturbation method and homotopy in topology. Many authors used this method to solve different classes of problems [18-22]. A few interesting studies about non-Newtonian can be obtained from $[23,24]$. Some interesting applications of engineering problems is studied by [25-33].

In view of the above literature, it is observed that the study of porous disks with Casson fluid with heat model is not carried so far, further this type of flows have lot of importance and application in engineering and technology so, the present study adds its findings on Casson fluid model to the existing knowledge base.

\section{Problem Formulation}

The problem of the Casson fluid between parallel circular non-conducting disks in the presence of a uniform strong magnetic field is investigated for small Reynolds number. The flow under consideration is entirely due to either uniform suction or injected at the disks as shown in Figure 1.

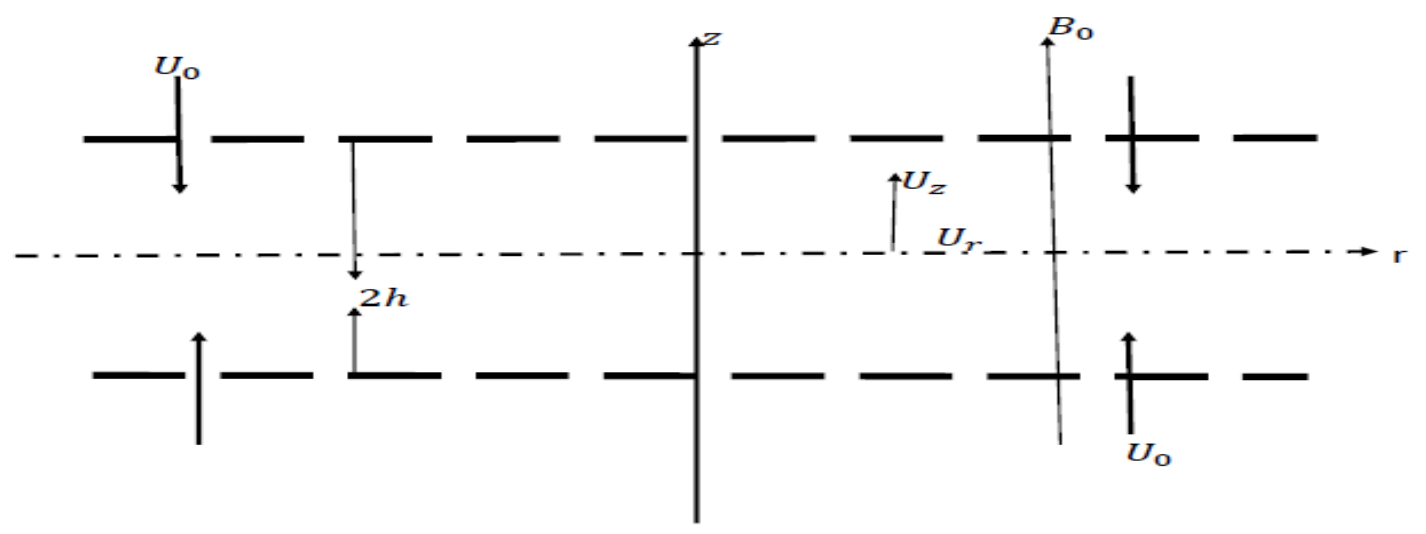

Fig. 1. Geometry of the problem

The governing equations of motion are

$$
\begin{aligned}
& U_{r} \frac{\partial U_{r}}{\partial r}+\frac{U_{z}}{h} \frac{\partial U_{r}}{\partial \eta}=-\frac{1}{\rho} \frac{\partial p}{\partial r}+v\left(1+\frac{1}{\gamma}\right)\left[\frac{\partial^{2} U_{r}}{\partial r^{2}}+\frac{1}{r} \frac{\partial u_{r}}{\partial r}-\frac{U_{r}}{r}+\frac{1}{h^{2}} \frac{\partial^{2} U_{r}}{\partial \eta^{2}}\right]-\frac{\mu^{2} \sigma H_{0}^{2}}{\rho} U_{r} \\
& U_{r} \frac{\partial U_{z}}{\partial r}+\frac{U_{Z}}{h} \frac{\partial U_{z}}{\partial \eta}=-\frac{1}{\rho h} \frac{\partial p}{\partial \eta}+v\left(1+\frac{1}{\gamma}\right)\left[\frac{\partial^{2} U_{Z}}{\partial r^{2}}+\frac{1}{r} \frac{\partial U_{Z}}{\partial r}+\frac{1}{h^{2}} \frac{\partial^{2} U_{z}}{\partial \eta^{2}}\right]
\end{aligned}
$$


$\frac{\partial U_{r}}{\partial r}+\frac{U_{r}}{r}+\frac{1}{h} \frac{\partial U_{z}}{\partial \eta}=0$

The induced magnetic field is assumed to be small and it can be calculated, assuming the velocity $U_{r}$ known, from the Maxwell-Ampere's equation

$\frac{\partial^{2} h r}{\partial \eta^{2}}+\alpha \mu \sigma h \frac{\partial U_{r}}{\partial \eta}=0$

The boundary condition on $h_{r}$, if the disks are non-conducting, is

$h_{r}=0 \quad$ at the disks

The boundary conditions on $U_{r}$ and $U_{z}$ are the no-slip conditions

$U_{r}(r, \pm h)=0$

and

$U_{z}(r, \pm h)=\mp U_{0}=$ constant

The equation for the temperature field, neglecting the viscous dissipation, can be written as

$\rho c_{p}\left(u \frac{\partial T}{\partial r}+\frac{w}{a} \frac{\partial T}{\partial \eta}\right)-k_{0}\left(\frac{1}{a^{2}} \frac{\partial^{2} T}{\partial \eta^{2}}+\frac{\partial^{2} T}{\partial r^{2}}+\frac{1}{r} \frac{\partial T}{\partial r}\right)=0$.

The boundary conditions for the temperature field can be written as

$T=\left\{\begin{array}{c}T_{1} \eta=1 \\ T_{2} \eta=-1\end{array}\right.$

Using the transformation

$\Phi(r, \eta)=\frac{U_{0} r^{2}}{2} f(\eta)$

$\theta(\eta)=\frac{T-T_{1}}{T_{2}-T_{1}}$

such that

$U_{r}=\frac{1}{r h} \frac{\partial \Phi}{\partial \eta}=\frac{U_{0} r}{2 h} f^{\prime}(\eta)$

and

$U_{z}=-\frac{1}{r} \frac{\partial \Phi}{\partial r}=-U_{0} f(\eta)$.

Eq. (1) and (2), using Eq. (9) and Eq. (10), becomes 
$\frac{U_{0} r}{2 h}\left[\frac{U_{0}}{2 h} f^{\prime}(\eta)^{2}-\frac{U_{0}}{h} f f^{\prime \prime}-\frac{v}{h^{2}} f^{\prime \prime \prime}+\frac{\mu^{2} \sigma H_{0}^{2}}{\rho} f^{\prime}\right]=-\frac{1}{\rho} \frac{\partial p}{\partial r}$

and

$\frac{U_{0}^{2}}{h} f f^{\prime}+\frac{v U_{0}}{h^{2}} f^{\prime \prime}=-\frac{1}{\rho h} \frac{\partial p}{\partial \eta}$

Since the right hand side of Eq. (12) is a function of $\eta$ only, it follows that

$\frac{\partial^{2} p}{\partial r \partial \eta}=0$

Hence, Eq. (11), using Eq. (13), becomes

$\frac{U_{0} r}{2 h} \frac{\partial}{\partial \eta}\left[\frac{U_{0}}{2 h} f^{\prime}(\eta)^{2}-\frac{U_{0}}{h} f f^{\prime \prime}-\frac{\nu}{h^{2}} f^{\prime \prime \prime}+\frac{\mu^{2} \sigma H_{0}^{2}}{\rho} f^{\prime}\right]=0$.

Eq. (14) is true for all $r$, if

$\left(1+\frac{1}{\gamma}\right) f^{\prime \prime \prime}(\eta)+R\left(f(\eta) f^{\prime \prime}(\eta)-\frac{1}{2} f^{\prime}(\eta)^{2}\right)-M^{2} f^{\prime}(\eta)=A$

$\theta^{\prime \prime}(\eta)+R P_{r} f(\eta) \theta^{\prime}(\eta)=0$

The boundary conditions on $f(\eta)$ and $\theta(\eta)$ are

$f( \pm 1)= \pm 1, \quad f^{\prime}( \pm 1)=0$

$\theta(-1)=0, \quad \theta(1)=1$

\section{Results and Discussion}

In this article we made an attempt to study the non-Newtonian Casson fluid flow between porous disks in the presence of heat transfer and magnetic field through HPM. In this section of the article we explain the solution of the consider problem and illustrate the results in graphical and tabular forms. To understand the characteristics of non-Newtonian Casson fluid with the presence of heat and magnet, we choose to present the shear stress, velocity and temperature across the disks for a range of Reynolds number $R$, the magnetic parameter $M$ and the Prandtl number $P_{r}$. The results presented using the homotopy perturbation series' method by considering 20 terms in the series and compared the results obtained by HPM with the classical FDM, by dividing the interval into 10000 sub-intervals. The algebra becomes cumbersome after certain steps we implement these two methods in mathematica software, by writing elegant code. We solved the consider problem using HPM and compared the results obtained from HPM using the classical FDM method. More about HPM for this class of problems one can refer the articles [34,35]. The zeroth and first order homotopy solution of Eq. (18) and Eq. (19), associated boundary conditions Eq. (20) and Eq. (21) as follows.

$f_{0}=\frac{1}{2}\left(3 \eta-\eta^{3}\right)$ 


$$
\begin{aligned}
& f_{1}=\frac{\gamma}{560(1+\gamma)}\left(-14 M^{2} \eta+19 R \eta+28 M^{2} \eta^{3}-39 R \eta^{3}-14 M^{2} \eta^{5}+21 R \eta^{5}-R \eta^{7}\right) \\
& f_{2}=\frac{1}{2587200(1+\gamma)^{2}}\left(3388 M^{4} \gamma^{2} \eta-2310 M^{2} R \gamma^{2} \eta-3288 R^{2} \gamma^{2} \eta-8316 \gamma^{2} M^{4} \eta^{3}\right. \\
& +13244 M^{2} \gamma^{2} R \eta^{3}-2215 R^{2} \gamma^{2} \eta^{3}+6468 M^{4} \gamma^{2} \eta^{5}-20328 M^{2} R \gamma^{2} \eta^{5} \\
& +15708 R^{2} \gamma^{2} \eta^{5}-1540 M^{4} \gamma^{2} \eta^{7}+10164 M^{2} \gamma^{2} R \eta^{7}-11682 \gamma^{2} R^{2} \eta^{7} \\
& \left.-770 M^{2} \gamma^{2} R \eta^{9}+1540 \gamma^{2} R^{2} \eta^{9}-63 \gamma^{2} R^{2} \eta^{11}\right) \\
& \theta_{0}=\frac{1}{2}(1+\eta) \\
& \theta_{1}=\frac{1}{80}\left(9 P_{r} R \eta-10 P_{r} \eta^{3}+P_{r} R \eta^{5}\right) \\
& \theta_{2}=\frac{1}{403200(1+\gamma)}\left(-456 M^{2} P_{r} R \gamma \eta+613 P_{r} R^{2} \gamma \eta+1391 P^{2} R^{2} \eta+1391 P_{r}^{2} R^{2} \gamma \eta\right. \\
& +840 M^{2} P_{r} R \gamma \eta^{3}-11340 P_{r} R^{2} \eta^{3}-1140 P_{r} R^{2} \gamma \eta^{3}-11340 P_{r} R^{2} \gamma \eta^{3} \\
& -504 M^{2} P_{r} R \gamma \eta^{5}+702 P_{r} R^{2} \gamma \eta^{5}+12474 P_{r}^{2} R^{2} \eta^{5}+12474 P_{r}^{2} R^{2} \gamma \eta^{5} \\
& +120 M^{2} P_{r} \gamma R \eta^{7}-180 P_{r} R^{2} \gamma \eta^{7}-2700 P_{r}^{2} R^{2} \eta^{7}-2700 P_{r}^{2} R^{2} \gamma \eta^{7}+5 P_{r} R^{2} \gamma \eta^{9} \\
& \left.+175 P_{r}^{2} R^{2} \eta^{9}+175 P_{r}^{2} R^{2} \gamma \eta^{9}\right)
\end{aligned}
$$

Figure 2 to 9 represent the dimensionless axial and redial velocity for various of parameters. Figure 2, 4, 6, 8 represents the dimensionless axial velocity, from these figures it is clear that the axial velocity takes its dimensionless value 1 , at the upper disk and -1 , at the lower disk and velocity of the fluid is decrease with increase in $\mathrm{R}$ in the domain $-1 \leq \eta \leq 0$ and opposite behavior is observed in $0 \leq \eta \leq 1$. Figure $3,5,7$ and 9 represent the behaviour of the radial velocity for various values of parameters. The radial velocity profiles are in the parabolic nature of all the values of the parameters. The radial velocity increases in the central plane and near the boundary, it falls with an increase in the values of $R$.

Figure 10 to 13 represent the variation of the temperature for different values of the parameters. From these figures we observed that the temperature profiles decrease in the region $-1 \leq \eta \leq 0$ with an increase in $R$ and opposite behavior we observed in $0 \leq \eta \leq 1$. Also, one can observe as increasing in the $P_{r}$ and $\gamma$ the temperature profile various this because of the non -Newtonian characteristic of the fluid. Table 1 and Table 2 show the heat transfer rate $\theta^{\prime}(-1)$. In this section we compared the results obtained by the HPM with the classical FDM technique and tabulated the values and the results are in good agreement. From Table 1 it is clear that the heat transfer rate decreases with increase in $R$. As we increase the magnetic parameter, heat transfer rate also increases, however, as we increase the Prandtl and Casson parameter $\gamma$ number heat transfer rate decreases. Table 3 shows the shear stress at lower disk results are calculated using HPM and compared with classical FDM. From Table 3 it is clear that shear stress decreases as $R \& \gamma$ increases, but it increases as $M$ increases. 


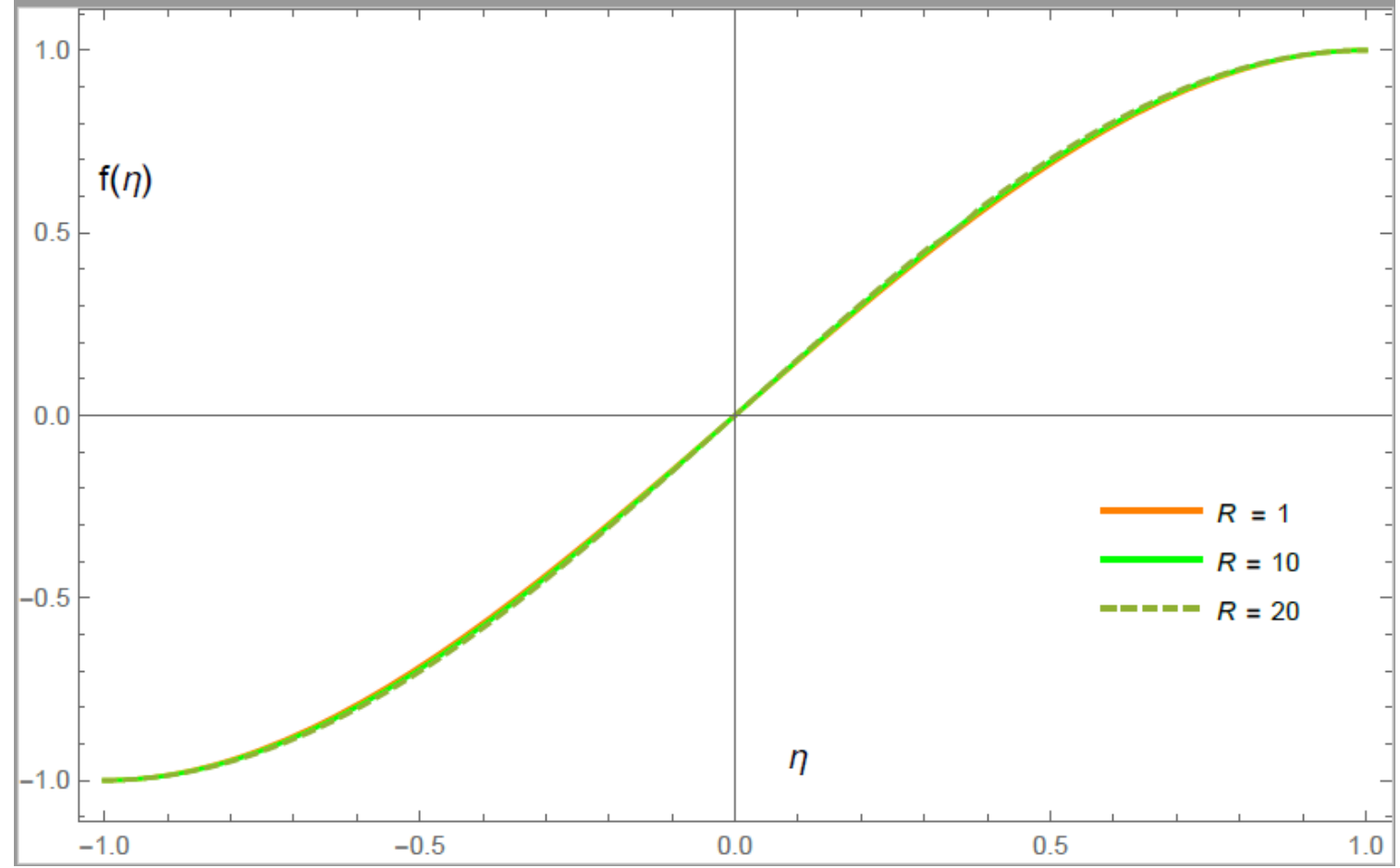

Fig. 2. fluid flow function $f(\eta)$ for $\gamma=0.1, M=0.2$

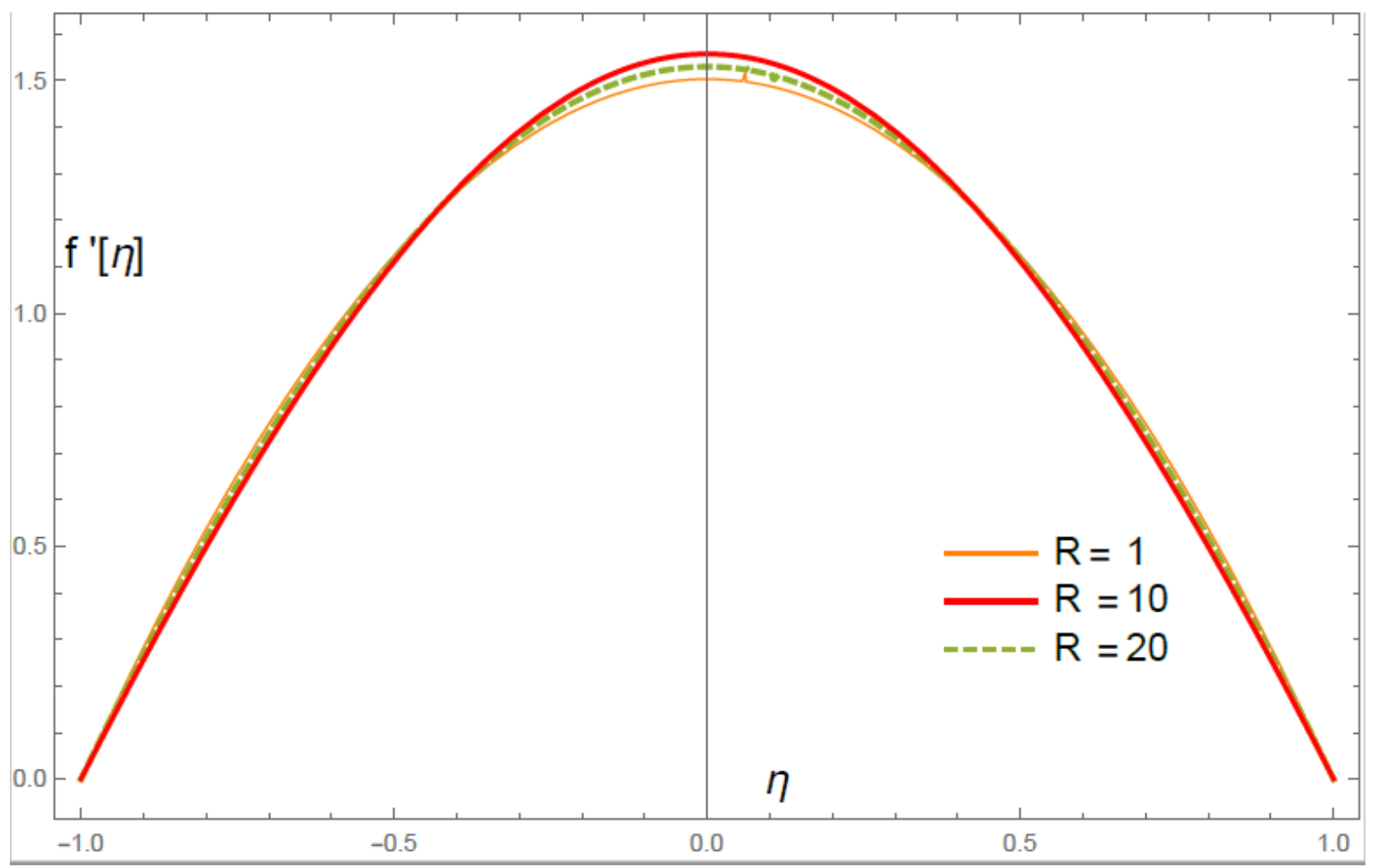

Fig. 3. Velocity function $f^{\prime}(\eta)$ for $\gamma=0.1, M=0.2$ 


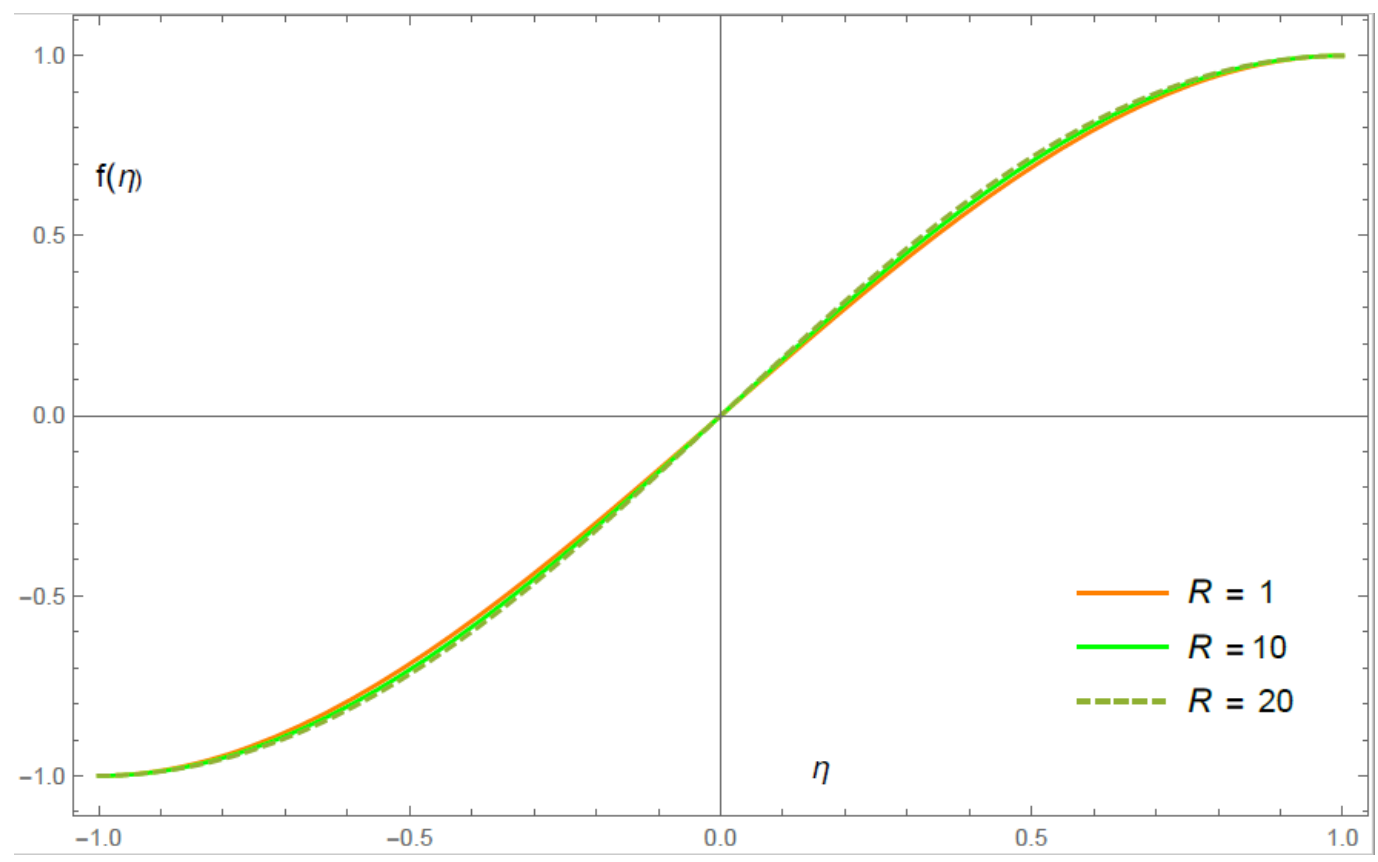

Fig. 4. Velocity function $f(\eta)$ for $\gamma=0.3, M=0.2$

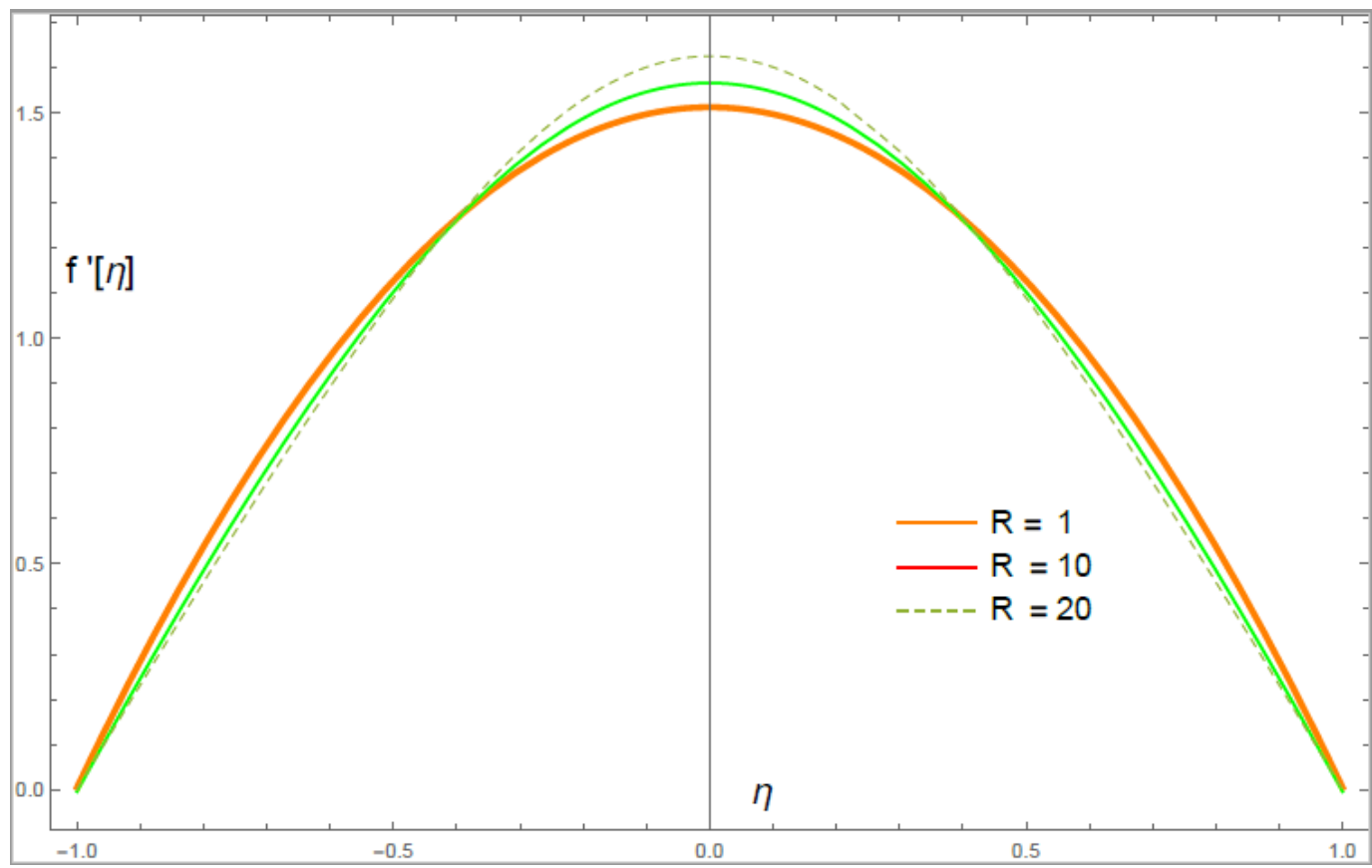

Fig. 5. Velocity function $f^{\prime}(\eta)$ for $\gamma=0.1, M=0.2$ 


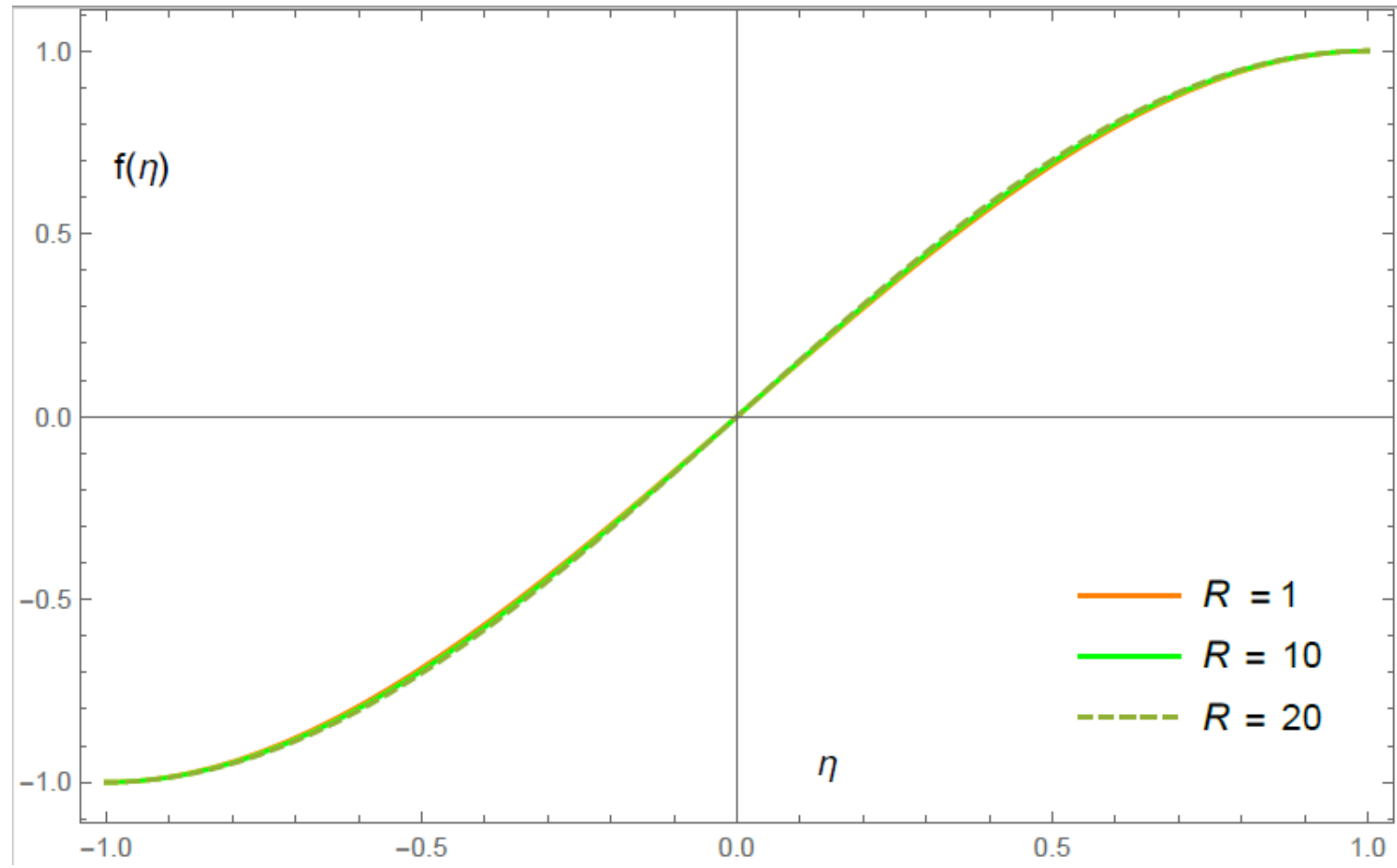

Fig. 6. Velocity function $f(\eta)$ for $\gamma=0.1, M=0.4$

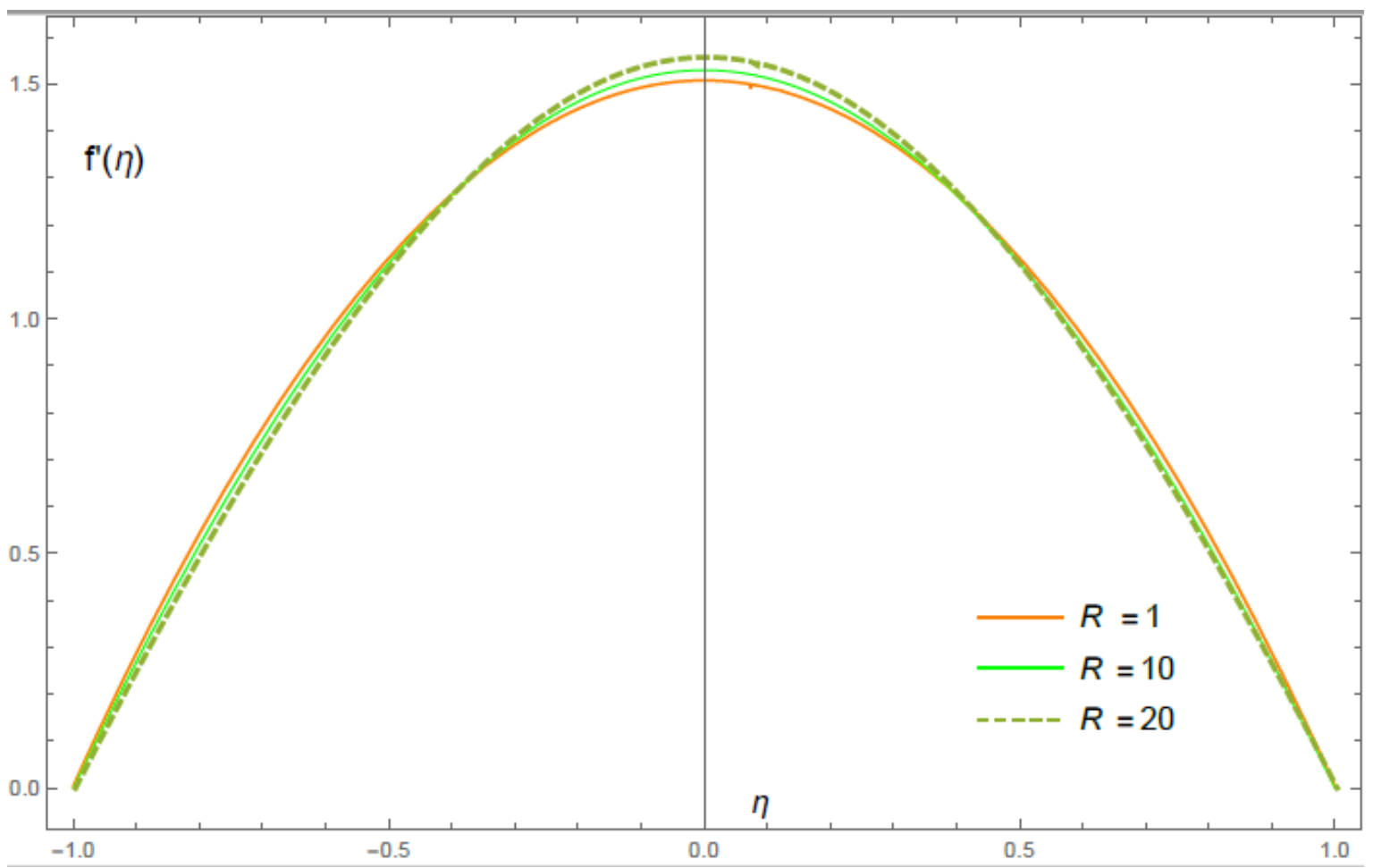

Fig. 7. Velocity function $f^{\prime}(\eta)$ for $\gamma=0.1, M=0.4$ 


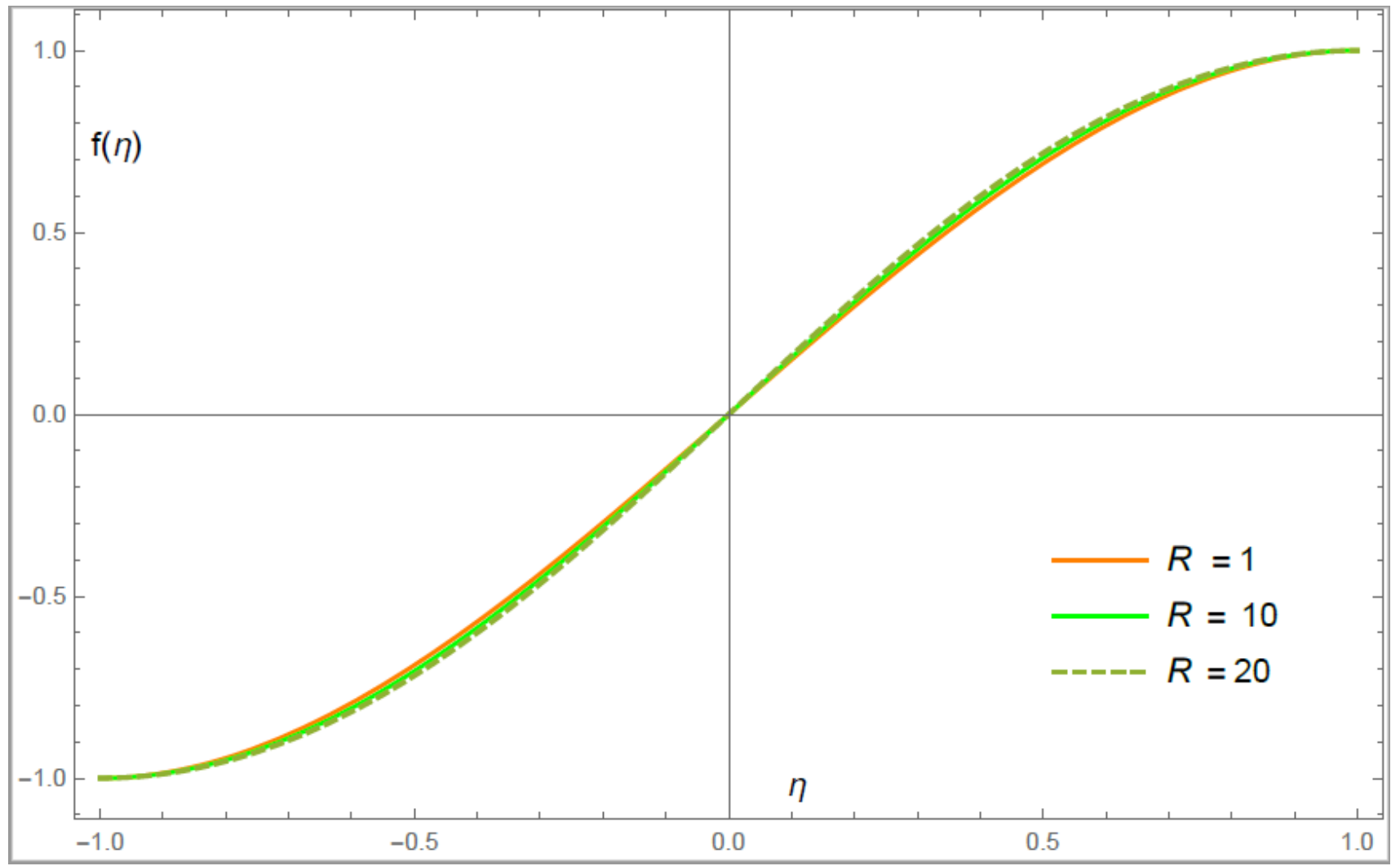

Fig. 8. Velocity function $f(\eta)$ for $\gamma=0.3, M=0.4$

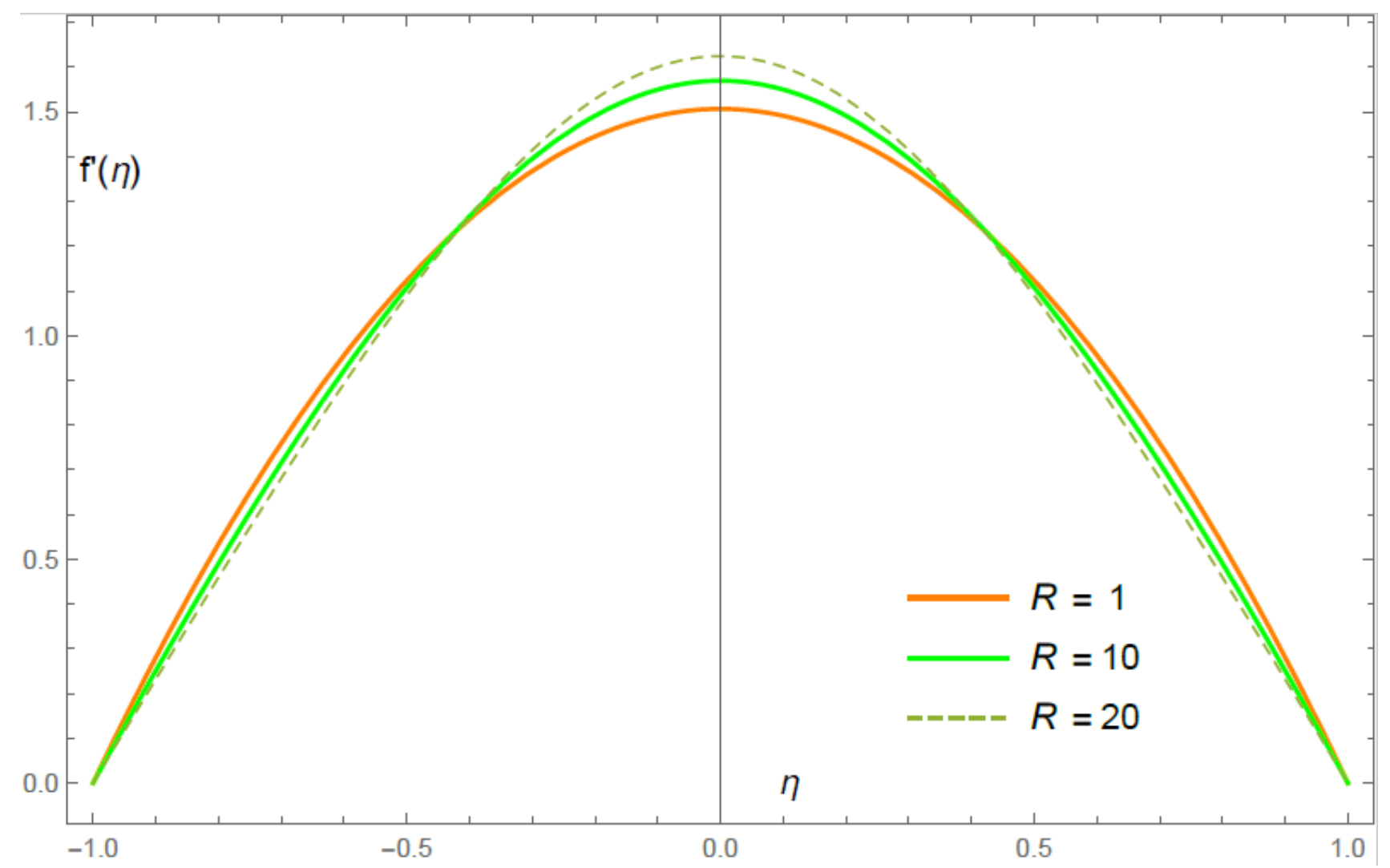

Fig. 9. Velocity function $f^{\prime}(\eta)$ for $\gamma=0.3, M=0.4$ 


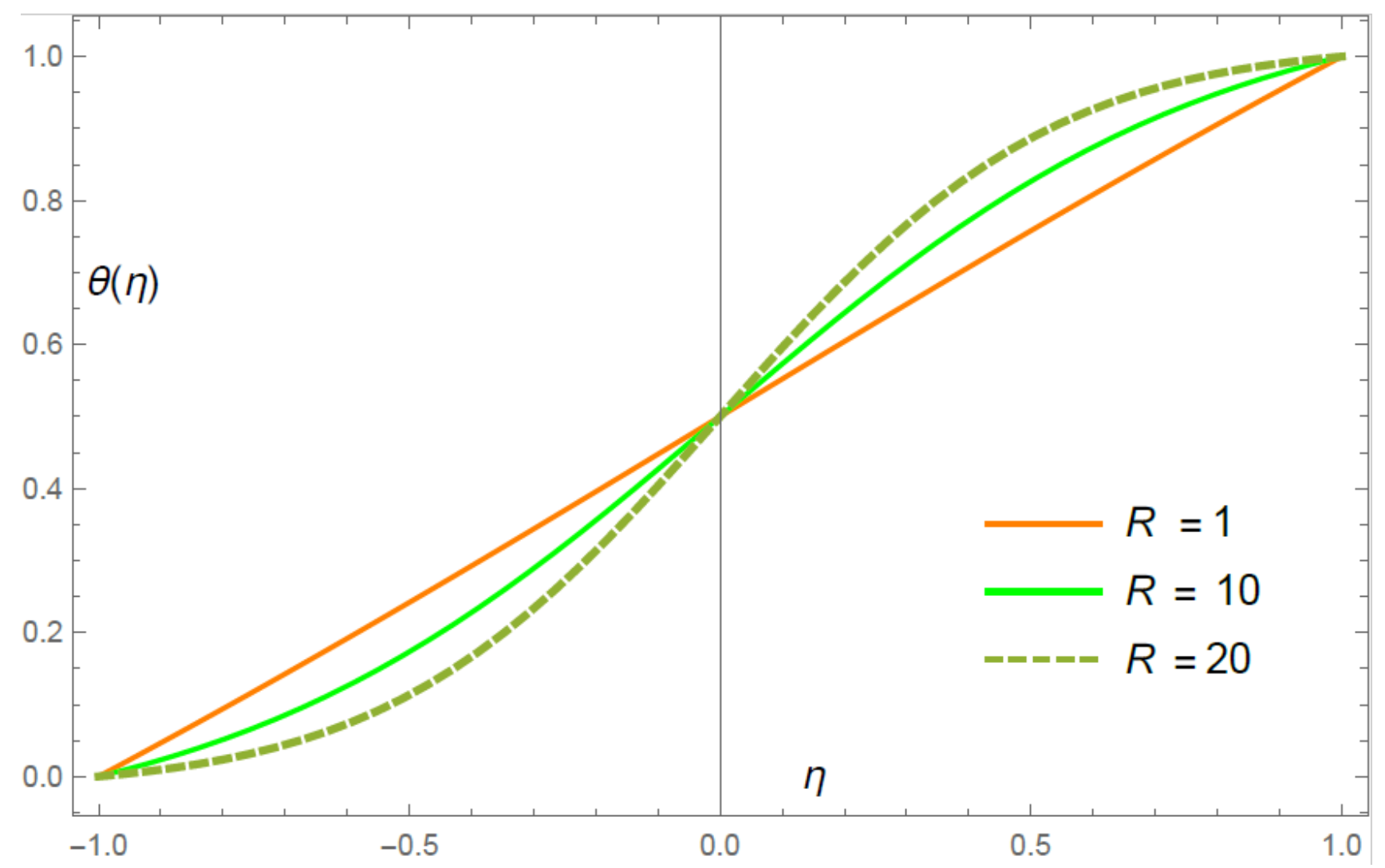

Fig. 10. Variation of $\theta(\eta)$ for $\gamma=0.1, M=0.1, P_{r}=0.2$

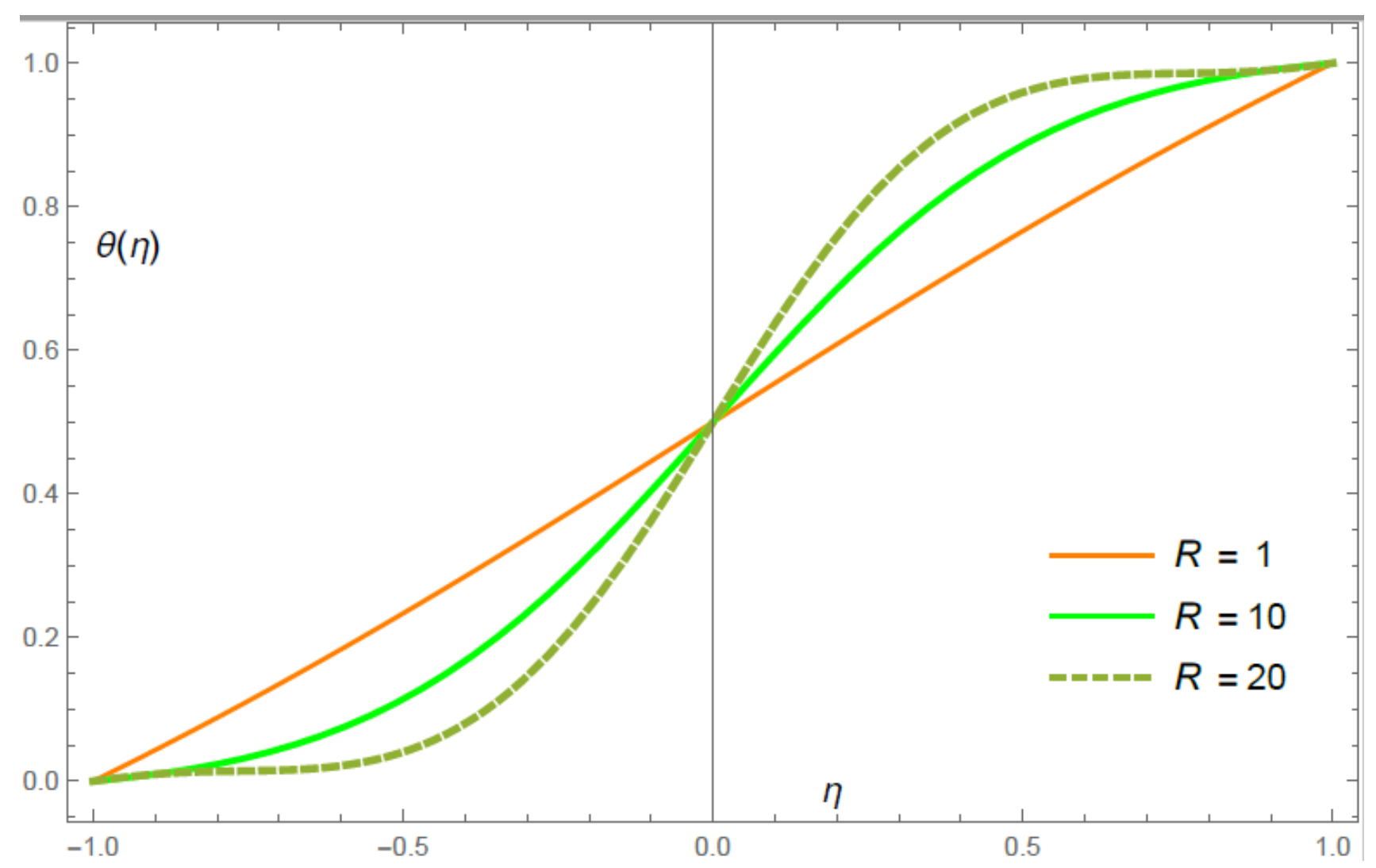

Fig. 11. Variation of $\theta(\eta)$ for $\gamma=0.1, M=0.1, P_{r}=0.4$ 


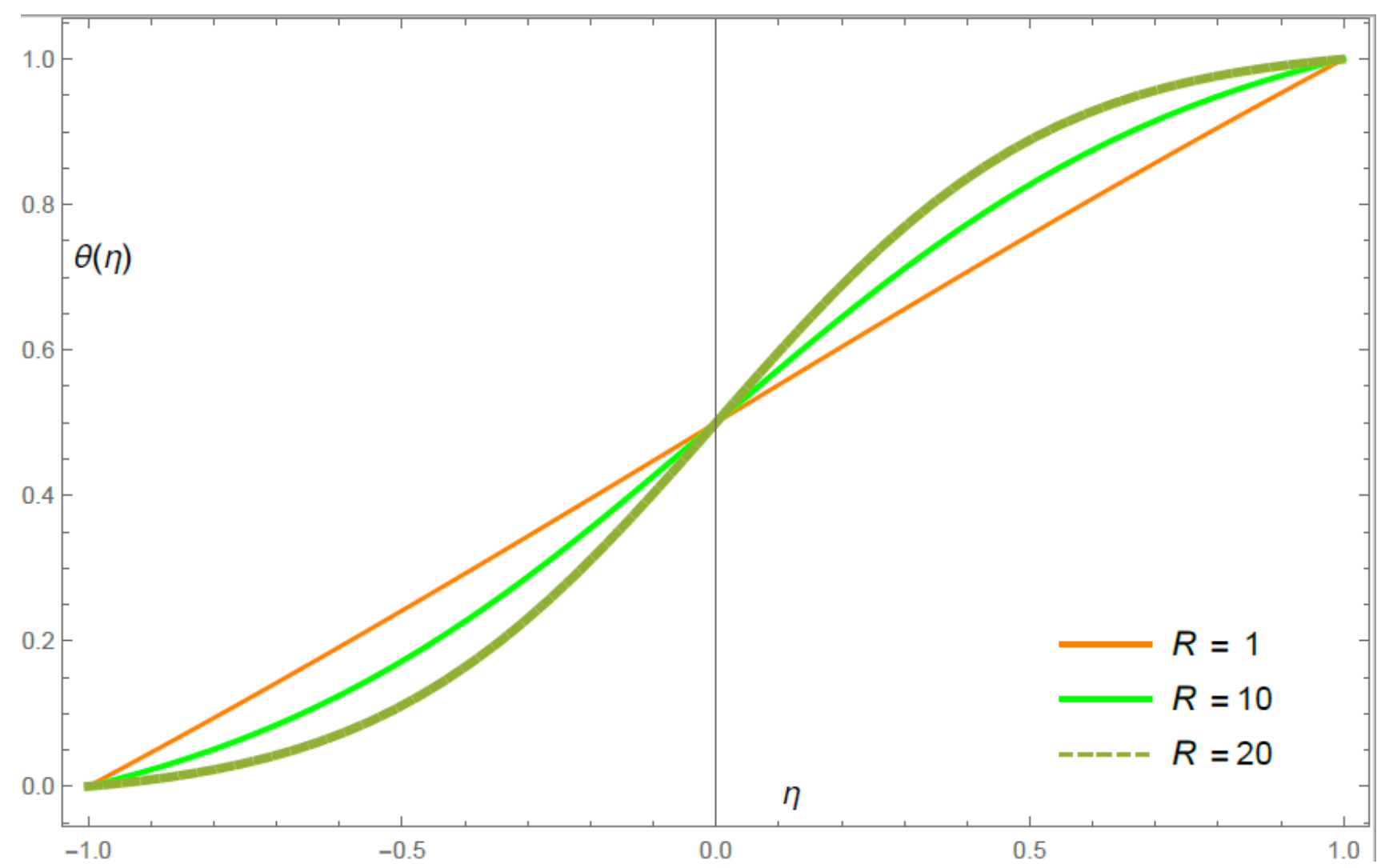

Fig. 12. Variation of $\theta(\eta)$ for $\gamma=0.3, M=0.1, P_{r}=0.2$

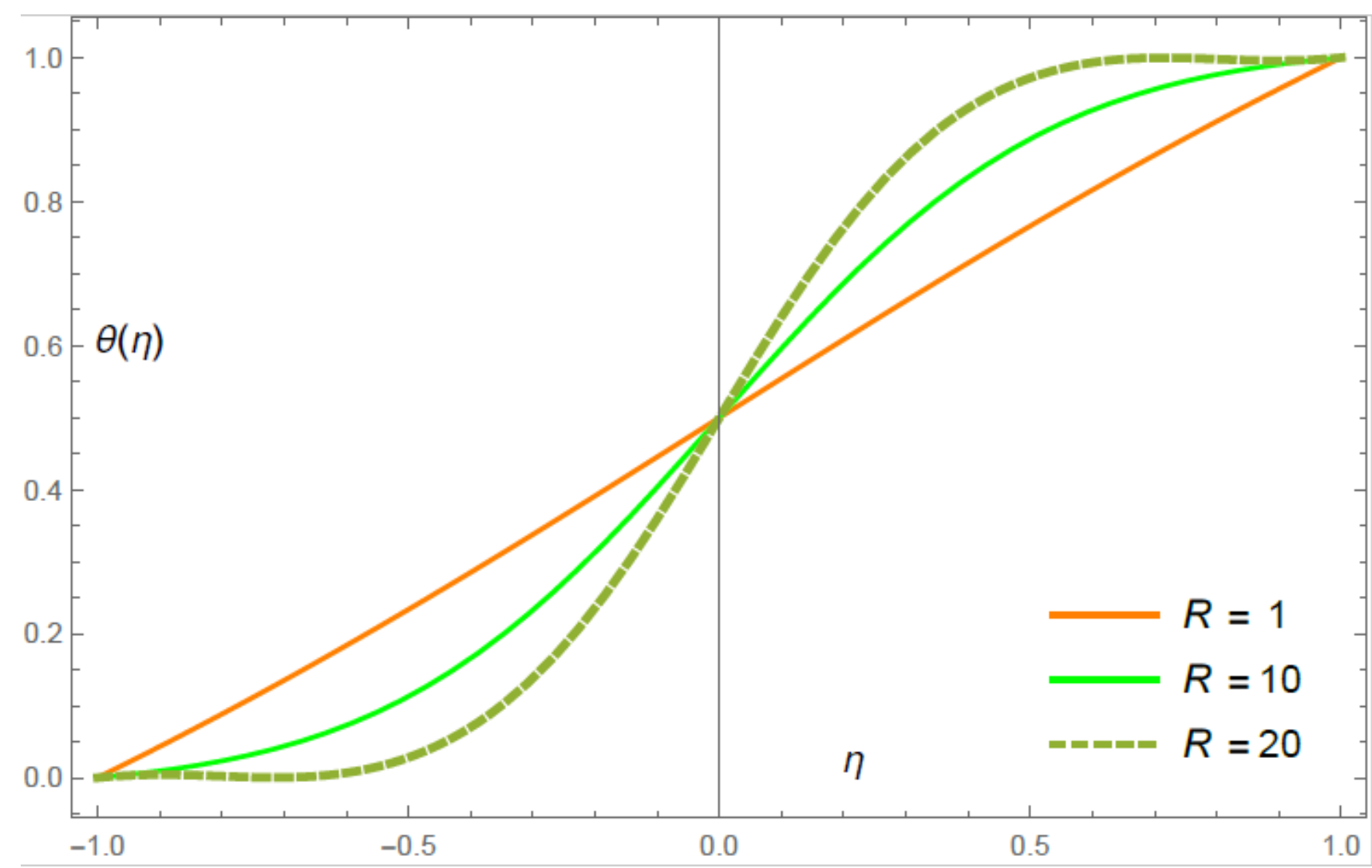

Fig. 13. Variation of $\theta(\eta)$ for $\gamma=0.3, M=0.1, P_{r}=0.4$ 
Table 1

Heat transfer rate $\theta^{\prime}(-1)$ for $\gamma=0.1$

\begin{tabular}{llllllll}
\hline$R$ & $P_{r}$ & $M$ & HPM & FDM & M & HPM & FDM \\
\hline 1 & 0.1 & 0.2 & 0.48029 & 0.48025 & 0.8 & 0.48030 & 0.48025 \\
2 & & & 0.46118 & 0.46114 & & 0.46119 & 0.46115 \\
3 & & & 0.44264 & 0.44261 & & 0.44265 & 0.44263 \\
4 & & & 0.42467 & 0.42465 & & 0.42469 & 0.42467 \\
5 & & & 0.40727 & 0.40725 & & 0.40730 & 0.40728 \\
6 & & & 0.39043 & 0.39041 & & 0.39046 & 0.39044 \\
7 & & & 0.37414 & 0.37412 & & 0.37417 & 0.37415 \\
8 & & & 0.35838 & 0.35838 & & 0.35814 & 0.35841 \\
9 & & & 0.34316 & 0.34316 & & 0.34319 & 0.34319 \\
10 & & & 0.32845 & 0.32845 & & 0.32849 & 0.32849 \\
1 & 0.4 & 0.2 & 0.42479 & 0.42477 & 0.8 & 0.42481 & 0.42479 \\
2 & & & 0.35880 & 0.35879 & & 0.35883 & 0.35882 \\
3 & & & 0.30136 & 0.30136 & & 0.30140 & 0.30141 \\
4 & & & 0.25177 & 0.25178 & & 0.25182 & 0.25184 \\
5 & & & 0.20929 & 020930. & 0.20934 & 0.20936 \\
6 & & & 0.17315 & 0.17317 & & 0.17321 & 0.17323 \\
7 & & & 0.14262 & 0.14264 & & 0.14267 & 0.14269 \\
8 & & & 0.11698 & 0.11701 & & 0.11704 & 0.11706 \\
9 & & & 0.09559 & 0.09561 & & 0.09564 & 0.09567 \\
10 & & & 0.07783 & 0.77850 & & 0.07788 & 0.07790 \\
\hline
\end{tabular}

Table 2

Heat transfer rate $\theta^{\prime}(-1)$ for $\gamma=0.3$

\begin{tabular}{|c|c|c|c|c|c|c|c|}
\hline$R$ & $P_{r}$ & $M$ & HPM & FDM & $\mathrm{M}$ & HPM & FDM \\
\hline 1 & 0.1 & 0.2 & 0.48028 & 0.48024 & 0.8 & 0.48029 & 0.48025 \\
\hline 2 & & & 0.46111 & 0.46108 & & 0.46114 & 0.46115 \\
\hline 3 & & & 0.44250 & 0.44247 & & 0.44254 & 0.44263 \\
\hline 4 & & & 0.42444 & 0.42442 & & 0.42449 & 0.42467 \\
\hline 5 & & & 0.40693 & 0.40691 & & 0.40699 & 0.40728 \\
\hline 6 & & & 0.38996 & 0.38995 & & 0.39003 & 0.39044 \\
\hline 7 & & & 0.37353 & 0.37352 & & 0.37361 & 0.37415 \\
\hline 8 & & & 0.35764 & 0.35764 & & 0.35772 & 0.35841 \\
\hline 9 & & & 0.34227 & 0.34227 & & 0.34235 & 0.34319 \\
\hline 10 & & & 0.32742 & 0.32741 & & 0.32751 & 0.32849 \\
\hline 1 & 0.4 & 0.2 & 0.42473 & 0.42471 & 0.8 & 0.42478 & 0.42476 \\
\hline 2 & & & 0.35858 & 0.35858 & & 0.35867 & 0.35866 \\
\hline 3 & & & 0.30094 & 0.30095 & & 0.30105 & 0.30105 \\
\hline 4 & & & 0.25114 & 0.25116 & & 0.25127 & 0.25128 \\
\hline 5 & & & 0.20845 & 0.20847 & & 0.20859 & 0.20861 \\
\hline 6 & & & 0.17214 & 0.17216 & & 0.17228 & 0.17230 \\
\hline 7 & & & 0.14148 & 0.14149 & & 0.14162 & 0.14163 \\
\hline 8 & & & 0.11576 & 0.11579 & & 0.11590 & 0.11590 \\
\hline 9 & & & 0.09432 & 0.09434 & & 0.09444 & 0.09446 \\
\hline 10 & & & 0.07655 & 0.07656 & & 0.07667 & 0.07668 \\
\hline
\end{tabular}


Table 3

Shear stress at the lower disk $\mathrm{f}^{\prime \prime}(-1)$

\begin{tabular}{llllllll}
\hline$R$ & $\gamma$ & $M$ & HPM & FDM & M & HPM & FDM \\
\hline 1 & 0.1 & 0.2 & 2.97762 & 2.97710 & 0.8 & 2.98842 & 2.98786 \\
2 & & & 2.95505 & 2.95455 & & 2.96577 & 2.96534 \\
3 & & & 2.93301 & 2.93235 & & 2.94364 & 2.94354 \\
4 & & & 2.91149 & 2.91067 & 2.92204 & 2.92156 \\
5 & & & 2.89049 & 2.88964 & & 2.90095 & 2.90038 \\
6 & & & 2.86999 & 2.86945 & 2.88036 & 2.87997 \\
7 & & & 2.84998 & 2.84945 & 2.86027 & 2.85962 \\
8 & & & 2.83047 & 2.83043 & 2.84066 & 2.84045 \\
9 & & & 2.81143 & 2.81114 & 2.82153 & 2.82129 \\
10 & & & 2.79286 & 2.79232 & & 2.80287 & 2.80238 \\
1 & 0.3 & 0.2 & 2.94421 & 2.94357 & 0.8 & 2.97123 & 2.97081 \\
2 & & & 2.88997 & 2.88954 & & 2.91643 & 2.91588 \\
3 & & & 2.83897 & 2.83872 & 2.86487 & 2.86423 \\
4 & & 2.79107 & 2.79091 & 2.81640 & 2.81604 \\
5 & & 2.74612 & 2.74566 & 2.77088 & 2.77027 \\
6 & & 2.70398 & 2.70324 & 2.72816 & 2.72761 \\
7 & & 2.66449 & 2.66387 & 2.68811 & 2.68741 \\
8 & & 2.62753 & 2.62759 & 2.65058 & 2.64988 \\
9 & & 2.59295 & 2.59294 & 2.61544 & 2.61472 \\
10 & & 2.56060 & 2.55978 & 2.58254 & 2.58207 \\
\hline
\end{tabular}

\section{Conclusions}

A careful observation on existing information / literature and the current study and results for parameters reveal the following.

i. This study indicates that shear stress decreases with increase in Reynolds numbers for fixed $M \& \gamma$. This characteristic enhances the importance of Casson fluid models.

ii. The results for axial velocity reveal that it increases in the range -1 to 0 and decreases thereafter, but functional values increase with an increase in the value of the independent variable in the domain. This feature shows, even in increase of Hartmann number and Prandtl number, the flow is smooth and normal. This feature increases the efficiency of the models over Newtonian models.

iii. For small value of $\mathrm{R}, \theta$ value variation is like a straight line, but as $\mathrm{R}$ increases with independent variable the variation becomes curved like the exterior of a circle. The results related to axial velocity behavior pattern also encourages the study of Casson fluid model.

iv. The heat transfer rate decreases with increase in $R$ for fixed values of $M, \gamma \& P_{r}$.

\section{Acknowledgements}

The authors thank the management of the University (MAHE) for the constant Encouragements to conduct of research.

\section{References}

[1] Kármán, Th V. "Über laminare und turbulente Reibung." ZAMM-Journal of Applied Mathematics and Mechanics/Zeitschrift für Angewandte Mathematik und Mechanik 1, no. 4 (1921): $233-252$. https://doi.org/10.1002/zamm.19210010401

[2] Batchelor, Cx K., and G. K. Batchelor. An introduction to fluid dynamics. Cambridge university press, 2000. https://doi.org/10.1017/CBO9780511800955 
[3] Lance, G. N., and Moi H. Rogers. "The axially symmetric flow of a viscous fluid between two infinite rotating disks." Proceedings of the Royal Society of London. Series A. Mathematical and Physical Sciences 266, no. 1324 (1962): 109-121. https://doi.org/10.1098/rspa.1962.0050

[4] Mellor, G. L., P. J. Chapple, and V. K. Stokes. "On the flow between a rotating and a stationary disk." Journal of Fluid Mechanics 31, no. 1 (1968): 95-112. https://doi.org/10.1017/S0022112068000054

[5] Root, N. and Lewellen, W. S. "Flow between a rotating stationary disk." Prog Aero Sci 36, no. 7 (1966).

[6] Wang, Chang-Yi, and Francis Skalak. "Fluid injection through one side of a long vertical channel." AlChE Journal 20, no. 3 (1974): 603-605. https://doi.org/10.1002/aic.690200326

[7] Wang, C-Y. "The squeezing of a fluid between two plates." (1976): 579-583. https://doi.org/10.1115/1.3424406

[8] Skalak, F. M., and C. Y. Wang. "On the unsteady squeezing of a viscous fluid from a tube." The ANZIAM Journal 21, no. 1 (1979): 65-74. https://doi.org/10.1017/S0334270000001922

[9] Srivastava, A. C., and S. K. Sharma. "Effect of transverse magnetic field on flow between two infinite discs-one rotating and other at rest." Bull. Acad. Pol. Sci., Ser. Sci. Tech.;(Poland) 9, no. 11 (1961).

[10] Stephenson, C. J. "Magnetohydrodynamic flow between rotating coaxial disks." Journal of Fluid Mechanics 38, no. 2 (1969): 335-352. https://doi.org/10.1017/S0022112069000206

[11] Chandrasekhara, B. C., and N. Rudraiah. "Magnetohydrodynamic laminar flow between porous disks." Applied Scientific Research 23, no. 1 (1971): 42-52. https://doi.org/10.1007/BF00413186

[12] Chandrasekhara, B. C., and N. Rudraiah. "Three dimensional magnetohydrodynamic flow between two porous disks." Applied Scientific Research 25, no. 1 (1972): 179-192. https://doi.org/10.1063/1.2975972

[13] Stewartson, K. "On the flow between two rotating coaxial disks." In Mathematical Proceedings of the Cambridge Philosophical Society, vol. 49, no. 2, pp. 333-341. Cambridge University Press, 1953. https://doi.org/10.1063/1.2975972

[14] Casson, N. "A flow equation for pigment-oil suspensions of the printing ink type." Rheology of disperse systems (1959).

[15] Vlachopoulos, Charalambos, Michael O'Rourke, and Wilmer W. Nichols. McDonald's blood flow in arteries: theoretical, experimental and clinical principles. CRC press, 2011. https://doi.org/10.1201/b13568

[16] Merrill, E. W., A. M. Benis, E. R. Gilliland, T. K. Sherwood, and E. W. Salzman. "Pressure-flow relations of human blood in hollow fibers at low flow rates." Journal of Applied Physiology 20, no. 5 (1965): 954-967. https://doi.org/10.1152/jappl.1965.20.5.954

[17] He, Ji-Huan. "Recent development of the homotopy perturbation method." Topological methods in nonlinear analysis 31, no. 2 (2008): 205-209.

[18] Gupta, Sumit, Devendra Kumar, and Jagdev Singh. "Application of He's homotopy perturbation method for solving nonlinear wave-like equations with variable coefficients." International Journal of Advances in Applied Mathematics and Mechanics 1, no. 2 (2013): 65-79.

[19] Abbasbandy, S. "Application of He's homotopy perturbation method to functional integral equations." Chaos, Solitons \& Fractals 31, no. 5 (2007): 1243-1247. https://doi.org/10.1016/j.chaos.2005.10.069

[20] Ganji, D. D., and A. Sadighi. "Application of He's homotopy-perturbation method to nonlinear coupled systems of reaction-diffusion equations." International Journal of Nonlinear Sciences and Numerical Simulation 7, no. 4 (2006): 411-418. https://doi.org/10.1515/IJNSNS.2006.7.4.411

[21] Rafei, M., and D. D. Ganji. "Explicit solutions of Helmholtz equation and fifth-order KdV equation using homotopy perturbation method." International Journal of Nonlinear Sciences and Numerical Simulation 7, no. 3 (2006): 321 328. https://doi.org/10.1515/IJNSNS.2006.7.3.321

[22] Rafei, M., D. D. Ganji, and H. Daniali. "Solution of the epidemic model by homotopy perturbation method." Applied Mathematics and Computation 187, no. 2 (2007): 1056-1062. https://doi.org/10.1016/i.amc.2006.09.019

[23] Abubakar, S. B., and NA Che Sidik. "Numerical prediction of laminar nanofluid flow in rectangular microchannel heat sink." Journal of Advanced research in fluid mechanics and thermal sciences 7, no. 1 (2015): 29-38.

[24] Gudekote, Manjunatha, and Rajashekhar Choudhari. "Slip effects on peristaltic transport of Casson fluid in an inclined elastic tube with porous walls." Journal of Advanced Research in Fluid Mechanics and Thermal Sciences 43, no. 1 (2018): 67-80.

[25] Abd El-Hameed, Afaf M., and Y. A. Abdel-Aziz. "Aluminium Alloys in Space Applications: A Short Report." Journal of Advanced Research in Applied Sciences and Engineering Technology 22, no. 1 (2021): 1-7.

[26] Phu, Nguyen Minh, Pham Ba Thao, and Duong Cong Truyen. "Heat and Fluid Flow Characteristics of Nanofluid in A Channel Baffled Opposite to The Heated Wall." CFD Letters 13, no. 1 (2021): 33-44. https://doi.org/10.37934/cfdl.13.1.3344

[27] Jasni, Nur Afiqah Husna, Siti Nur Fatin Zuikafly, Hafizal Yahaya, Mundzir Abdullah, and Fauzan Ahmad. "GrapheneSilver Based Passive Q-Switcher." Journal of Advanced Research in Materials Science 76, no. 1 (2021): 1-9. https://doi.org/10.37934/arms.76.1.19 
[28] Hamrayev, Hemra, Kamyar Shameli, and Mostafa Yusefi. "Preparation of Zinc Oxide Nanoparticles and its Cancer Treatment Effects: A Review Paper." Journal of Advanced Research in Micro and Nano Engineering 2, no. 1 (2020): 1-11. https://doi.org/10.37934/jrnn.1.1.6274

[29] Alawi, Omer A., and Haslinda Mohamed Kamar. "Performance of Solar Thermal Collector Using Multi-Walled Carbon Nanotubes: Simulation Study." Journal of Advanced Research in Micro and Nano Engineering 2, no. 1(2020): 12-21.

[30] Bakar, Norhaliza Abu, and Rozaini Roslan. "Mixed Convection in a Lid-Driven Horizontal Cavity in the Presence of Internal Heat Generation or Absorption." Journal of Advanced Research in Numerical Heat Transfer 3, no. 1 (2020): $1-11$.

[31] Sudarja, Sudarja, and Sukamta Sukamta. "Experimental Study on Flow Pattern and Void Fraction of Air-Water and 3\% Butanol Two-Phase Flow in 30o Inclined Mini Channel." Journal of Advanced Research in Experimental Fluid Mechanics and Heat Transfer 1, no. 1 (2020): 11-20.

[32] Hnin, Mya Thet, and Thein Min Htike. "Estimation of Rotating Unbalance in Rotor Bearing System using Operating Deflection Shape." Journal of Advanced Research in Applied Mechanics 71, no. 1 (2020): 11-23. https://doi.org/10.37934/aram.71.1.1123

[33] Sidik, NA Che, and O. Adnan Alawi. "Computational investigations on heat transfer enhancement using nanorefrigerants." Journal of Advanced Research Design 1, no. 1 (2014): 35-41.

[34] VS, Sampath Kumar, and Nithyananda P. Pai. "Suction and injection effect on flow between two plates with reference to Casson fluid model." Multidiscipline Modeling in Materials and Structures 3, no. 15 (2019): $558-574$. https://doi.org/10.1108/MMMS-05-2018-0092

[35] Kumar, VS Sampath, and N. P. Pai. "A study of magnetic effect on flow between two plates with suction or injection with special reference to casson fluid." Frontiers in Heat and Mass Transfer 12, no. 23 (2019): 559-574. http://doi.org/10.5098/hmt.12.23 